\title{
Formation of Variously Shaped Gold Nanoparticles by Anabaena laxa
}

\author{
Monika Lenartowicz ${ }^{1}$ Paulina H. Marek ${ }^{2}$. \\ Izabela D. Madura ${ }^{2}$ Jacek Lipok ${ }^{1}$ (D)
}

Received: 13 January 2017/Published online: 22 July 2017

(C) The Author(s) 2017. This article is an open access publication

\begin{abstract}
Anew aspect of this study is the biocatalysis ability of Anabaena laxafresh-water strain - which to date has not been studied with respect to the formation of gold nanoparticles. The results of our study have shown that A. laxa is able to form gold nanoparticles (AuNPs) at good yields within $24 \mathrm{~h}$ of incubation at all three tested concentrations $(0.1,0.5$ and $1 \mathrm{mM})$ of hydrogen tetrachloroaurate (III). After $24 \mathrm{~h}$, nanoparticles were mostly localized in the growth medium, which significantly facilitates their isolation. However, the elongation of this process is accompanied by their concentration in the exopolysaccharide (EPS) layer of the cyanobacterial cells. There is a correlation between the initial concentration of the $\mathrm{Au}^{3+}$ cations and the formation of AuNPs of various shapes and a size. The comparison of activities of living and deactivated cells indicated that AuNPs were formed more efficiently when metabolically active cyanobacteria were used.
\end{abstract}

Keywords Biocatalytic formation - Gold nanoparticles $\cdot$ Cyanobacteria $\cdot$ Anabaena laxa

Jacek Lipok

jacek.lipok@uni.opole.pl

Monika Lenartowicz

mostrowska@uni.opole.pl

1 Faculty of Chemistry, Opole University, Oleska 48, 45-052 Opole, Poland

2 Faculty of Chemistry, Warsaw University of Technology, Noakowskiego 3, 00-664 Warsaw, Poland 


\section{Introduction}

Although gold nanoparticles (AuNPs) have been known since antiquity, they are now one of the most investigated fields, which is confirmed by increasing numbers of publications [1]. The high interest in gold nanoparticles is due to their unique properties, which are determined by their morphology, mainly shape and size. These features strongly depend on their method of synthesis.

Currently, several (physical, chemical and biological) methods of synthesis of metallic nanoparticles are known. The most commonly used physico-chemical methods rely mostly on a bottom-up technique; oxidation/reduction processes are the major modes, in which metal cations are reduced to nanoparticles by various agents [2]. The most popular and well-defined nanoparticles are spherical which differ from each other mainly by size (diameter) and thus have found many applications in technology and medicine. Spherical nanoparticles are widely described in the literature and evidenced by almost 2500 review papers (Web of Science, September 2016). Nanoparticles of varying shapes, such as rods [3], cubes [4], triangular prisms [5] and branched nanocrystals [6], exhibit significantly different properties than spherical NPs [7], which are more pronounced in studies of their applications. The nanorodparticles possess a higher sensitivity to the local dielectric environment than spherical particles of a similar size. This feature makes them excellent colorimetric probes [8]. The AuNPs have found numerous applications in different disciplines of science and industry, such as: catalysis [9], detection of toxic ions [10], biosensors and bioprobes [11], molecular recognition [12], and nanoelectrodes [13]. Non-spherical particles also demonstrate catalytic activity on textured surfaces and the enhancement of the surface enhanced Raman spectroscopy SERS effect [14]. Some NPs have been examined as antibacterial agents [15, 16]. Extensive studies on irregular metallic NPs result from their possible application in biomedicine, since an important feature of these NPs is the appearance of a plasmon band in the near-infrared region. The adsorption of nearinfrared radiation by tissues is relatively low; therefore, the region between $800 \mathrm{~nm}$ and $1300 \mathrm{~nm}$ can be used for medicinal diagnostics. Due to this, metallic nanoparticles of various shapes may be used as contrast agents [17] in photothermal cancer therapy [18] and as nanocarriers for drug or gene delivery [19, 20].

Nanoparticles obtained by biological processes possess the same features and are applied in the same way as those synthesized by classic chemical methods $[15,16]$. Therefore, engaging various organisms, such as bacteria, fungi [21] and algae [22-24] to plants [25], is an interesting alternative to the chemical and physical methods of producing metal nanoparticles (MeNPs). This is because biological processes are relatively cheap, environmentally friendly, easy to prepare and less toxic. Biological processes can lead to nanoparticles suited for a wide range of applications due to their differing morphology $[15,26]$. The biological methods are also based on the reduction of starting metal cations, which are added to the medium containing live or dead microorganisms or secreted enzymatic cocktails [2]. The reduction of metal ions by microorganisms is one of their protective mechanisms, which are used to convert harmful chemicals into harmless substances [27]. The 
microbial process can be performed in two ways: in vitro with the use of some cell extracts or in vivo with the use of living cells [28]. Regarding the in vivo process, the biosynthesis of MeNPs may be classified as dependent on the location where nanoparticles are formed. The intracellular processes of formation comprise the transportation of ions into microbial cells to form nanoparticles due to the oxidoreductive activity of appropriate enzymes. Extracellular synthesis comprises the capturing of metal ions on the surface of the cells, followed by the reduction of cations [16]. The morphology of the biosynthesized nanoparticles depends on various parameters, such as temperature, $\mathrm{pH}$, the ratio between biomass and ion concentrations and the duration of the process $[12,28]$. The size and the shape are also dependent on the strain of microorganism used [29], which is probably related to the specificity of their enzymes and/or cell wall composition. Among microorganisms that are capable of synthesizing gold nanoparticles, a photoautotrophic bacterium, cyanobacteria, is gaining increasing interest. It was proven that the nitrogenases [EC 1.19.6.1] [EC 1.18.6.1] present in the specialized cyanobacterial cells, heterocysts, are taking part in bioreduction processes. Since nitrogenase uses the nitrogen in the ambient air as a substrate, there is no need to add an external reducing agent, as there is in case of hydrogenases, which always require the presence of hydrogen or other reducing agents [30]. However, the mentioned enzymes are not the main or only ones responsible for the production of AuNPs, since there is evidence that NPs obtained extracellularly are present mostly within vegetative cells and not in heterocysts $[22,28]$. The study of Dahoumane and coauthors proved that other types of microalgae, devoid of nitrogenases, offer a better yield of nanoparticles [24, 29, 31, 32]. Spirulina platensis is the most frequently mentioned cyanobacterial species able to produce AuNPs $[33,34]$ and thus can be regarded as a model microorganism in this group. Other species described in the literature include Nostoc ellipsosporum [35], Phormidium valderianum, Phormidium tenue [36], Anabaena flos-aquae [29] and Anabaena sp. [28].

Anabaena flos-aquae [29] and Anabaena sp. [28] have been described as species capable of reducing gold ions with the formation of spherical nanoparticles in most cases. The aim of our paper is to enlarge this family by adding Anabaena laxa (Braun) to the cyanobacterial species possessing this activity. The important issues of our study were the influence of the initial concentration of $\mathrm{Au}^{3+}$ on the morphology of the obtained gold nanoparticles and the efficiency of formation and stability of AuNPs in cyanobacterial media. Finally, we discuss the advantage using living cells in the synthesis of AuNPs in the context of the yield of this process.

\section{Materials and Methods}

\section{Cultivation of Cyanobacteria}

The strain of A. laxa was purchased from the Culture Collection of Autotrophic Organisms (CCALA), Institute of Botany, Academy of Sciences of the Czech Republic. The cultivation of the microorganism was conducted in BG11 (ATCC 616) medium, which is typically used for the cultivation of fresh-water species. The 
medium is composed of the optimal mixture of nutrients to support the growth of these organisms. The cultures of cyanobacteria were transferred to the fresh medium every 3 weeks (when they were still in exponential phase and in good metabolic conditions) in order to maintain the culture or obtain the microorganisms for experimental inoculation. Cyanobacteria were cultivated at $23 \pm 1{ }^{\circ} \mathrm{C}$ under $16 / 8 \mathrm{~h}$ day/night light conditions $\left(25 \mu \mathrm{mol} \mathrm{m} \mathrm{m}^{-2} \mathrm{~s}^{-1} \mathrm{PAR}\right)$ in $250 \mathrm{~mL}$ Erlenmeyer flasks containing $50 \mathrm{~mL}$ of fresh medium, which was inoculated with $10 \mathrm{~mL}$ of three-week-old culture. All activities related to the transfer of cyanobacterial cultures were performed under a laminar flow chamber using sterile glass and sterile equipment.

\section{Estimation of Total Chlorophyll Content in Experimental Inoculum}

The three-week-old cultures of cyanobacteria were centrifuged at $5000 \mathrm{rpm}$ for $1 \mathrm{~min}$, then the supernatants were removed and the cells were collected together due to obtained experimental inoculum. Next the three $1.0 \mathrm{~mL}$ portions of inoculum were centrifuged at 13,000 rpm for $5 \mathrm{~min}$ and the supernatants were removed. The cyanobacterial pellets in each sample were resuspended in $0.9 \mathrm{~mL}$ methanol and placed in the dark for $20 \mathrm{~min}$ with occasional stirring. After this time the methanol extracts were centrifuged in the same condition as described above, and the absorbances of the supernatants were measured at 645 and $663 \mathrm{~nm}$ against blank using a Hitachi U-2810 UV-Vis spectrophotometer (Warszawa, Poland) [37]. The concentrations $(\mu \mathrm{g} / \mathrm{mL})$ of the total chlorophyll were calculated based on Arnon's equation [38]:

$$
\mathrm{C}_{\text {chlorophyll }}=20.2 \cdot \mathrm{A}_{645}+8.02 \cdot \mathrm{A}_{663} .
$$

\section{Viability of $A$. laxa}

Cultivations of A. laxa were performed in $100 \mathrm{~mL}$ Erlenmeyer flasks containing $30 \mathrm{~mL}$ of fresh medium, which was supplemented with the appropriate volumes of 120 or $12 \mathrm{mM}$ stock solutions of hydrogen tetrachloroaurate (III) trihydrate$\mathrm{HAuCl}_{4} \cdot 3 \mathrm{H}_{2} \mathrm{O}$ (Sigma-Aldrich, Poznań, Poland) to obtain the final concentrations of $0.01 ; 0.05 ; 0.1 ; 0.5$ and $1.0 \mathrm{mM}$. The stock solutions were prepared by dissolving the $\mathrm{HAuCl}_{4}$ in deionized (Milipore Q) water, which was further sterilized by filtration through a sterile cellulose acetate membrane with a pore diameter of $0.20 \mu \mathrm{m}$ (Bionovo, Legnica, Poland). At the beginning of the experiment (day 0), each culture contained the same amount of living A. laxa cells, related to $5 \mu \mathrm{g}$ of chlorophyll in $1 \mathrm{~mL}$ of culture. All activities were performed in a laminar flow chamber using sterile equipment. Each experimental set was carried out at least in triplicate. The viability of cyanobacteria growing at $23 \pm 1{ }^{\circ} \mathrm{C}$, under $16 / 8 \mathrm{~h}$ day/ night light conditions $\left(250 \mu \mathrm{mol} \mathrm{m} \mathrm{m}^{-2} \mathrm{~s}^{-1}\right.$ PAR), was estimated on the basis of the chlorophyll content (an indicator of metabolic activity), which was measured on days $1,2,3,4,7,11$ and 14 . 


\section{Biosynthesis of Gold Nanoparticles by A. laxa}

Experimental cultivations were performed according to the procedure described above (Viability of $A$. laxa) but only for the final concentrations of $\mathrm{HAuCl}_{4}: 0.1,0.5$ and $1.0 \mathrm{mM}$. Each experiment was carried out at least in triplicate by cultivating the bacteria for $24 \mathrm{~h}$ or 14 days in order to obtain the cells and media for further analyses. For this purpose the appropriate samples were centrifuged at $5000 \mathrm{rpm}$ for $1 \mathrm{~min}$ and post-culture media were decanted and analysed using TEM and UV-Vis methods. The concentrated biomass was washed three times by resuspending the cells in deionized water followed by centrifugation and removal of supernatant. Cyanobacterial pellets were prepared for SEM analysis and for the extraction of gold nanoparticles.

To determine whether cyanobacterial cells influence the stability of formed gold nanoparticles, the following experiment was performed. The cultures of A. laxa were prepared according to the method described in the previous subsection, with the difference being in that the experimental set (one set contains three concentrations of gold ions in triplicate) was doubled. After $24 \mathrm{~h}$ of incubation, when the AuNPs were obtained, cyanobacterial cells were removed by filtration through cellulose acetate filters $(0.45 \mu \mathrm{m})$ (Bionovo, Legnica, Poland) from one of the sets. In the second set, the cells remained in the medium. Both sets were placed under the temperature and light conditions described previously for seven days. During this time, the UV-Vis spectra of 1-mL samples from each experiment (with or without microorganisms) were recorded on days $0,1,2,3,4$ and 7 . The samples containing cyanobacterial cells were filtered through cellulose acetate filters $(0.45 \mu \mathrm{m})$ before each spectroscopic measurement.

\section{Extraction of Gold Nanoparticles from Cyanobacterial Cells}

After 14 days of incubation, the cells were separated from the media by centrifugation $(5000 \mathrm{rpm}$ for $1 \mathrm{~min}$ ). They were transferred to $1 \mathrm{~mL}$ of $7.5 \mathrm{mM}$ sodium citrate solution (Sigma-Aldrich, Poznań, Poland) and placed in an ultrasonic bath for $30 \mathrm{~min}$. Sodium citrate is considered an environmentally friendly substance due to its lack of surfactant features and it is commonly used in the preparation of gold nanoparticles, mostly as a capping agent for their stabilization. For example, Parial and Pal successfully used a sodium citrate solution to extract gold nanoparticles from Spirulina subsalsa biomass [39]. Therefore, we decided to adapt this method for our purposes. After the ultrasound-assisted extraction, the samples were centrifuged (5000 rpm for $1 \mathrm{~min}$ ) and the supernatants were analysed by UV-Vis spectroscopy with respect to the presence of gold nanoparticles.

\section{Formation of Gold Nanoparticles Catalysed by Deactivated Cells of A. laxa}

The deactivation of cyanobacterial cells was performed either by freezing or with the application of high temperature. The chlorophyll content of the appropriate amount of concentrated cells was measured, and then the cells were divided into twenty-four portions. Every portion was treated as an inoculum, which if added to 
an experimental culture created the final concentration of chlorophyll of $5 \mu \mathrm{g} / \mathrm{mL}$. Twelve of those portions were then autoclaved at $126^{\circ} \mathrm{C}$ for $20 \mathrm{~min}$, and twelve others were frozen at $-23{ }^{\circ} \mathrm{C}$. Next, all these portions of deactivated cells were left to reach room temperature $\left(23^{\circ} \mathrm{C}\right)$ and were placed in the glass flasks filled with $30 \mathrm{~mL}$ of deionized water supplemented with hydrogen tetrachloroaurate, with final concentrations of $0.1,0.5$ or $1.0 \mathrm{mM}$. All samples were prepared in triplicate and were incubated alongside the appropriate controls (without gold cations) for $24 \mathrm{~h}$ in the temperature and light conditions described in the subsection Cultivation of cyanobacteria. After this time, the supernatants were separated from the cells and analysed by UV-Vis spectrophotometery in order to initially check for the presence of AuNPs and subsequently study the surface plasmon resonance (SPR) features.

\section{Characterization Techniques}

\section{UV-Visible Spectroscopy}

UV-Vis spectra were taken for three types of samples: (i) media, (ii) aqueous and (iii) citrate extracts from cyanobacterial cells. For this purpose, an aliquot of $1 \mathrm{~mL}$ solution was scanned in the range of $400-1000 \mathrm{~nm}$ in order to determine the spectrum of the gold nanoparticles formed by living $A$. laxa or in the range of $400-700 \mathrm{~nm}$ in the all other experiments using medium, water or stock solutions of sodium citrate, as blanks.

\section{X-ray Diffraction (XRD)}

The crystalline nature and the approximate size of AuNPs were determined by Xray diffraction studies. For XRD studies the portions of three samples $(0.1 ; 0.5$ and $1.0 \mathrm{mM}$ ) obtained by biosynthesis after incubation of gold ions (concentrations: 0.1 ; 0.5 and $1.0 \mathrm{mM}$ ) with $A$. laxa cells were lyophilized and analyzed. Laboratory powder X-ray diffraction patterns were recorded at room temperature on a Bruker D8 Advance diffractometer (Warsaw, Poland) equipped with a LYNXEYE position sensitive detector, using $\mathrm{Cu}-\mathrm{K} \alpha$ radiation $(\lambda=0.15418 \mathrm{~nm})$. The data were collected in the Bragg-Brentano $(\theta / \theta)$ horizontal geometry (flat reflection mode) between $7^{\circ}$ and $70^{\circ}(2 \theta)$ in a continuous scan, using $0.03^{\circ}$ steps $960 \mathrm{~s} / \mathrm{step}$. The diffractometer incident beam path was equipped with a $2.5^{\circ}$ Soller slit, and a $1.14^{\circ}$ fixed divergence slit, while the diffracted beam path was equipped with a programmable antiscatter slit (fixed at $2.20^{\circ}$ ), a Ni $\beta$-filter and a $2.5^{\circ}$ Soller slit. Data were collected under standard laboratory conditions (temperature and relative humidity). The size of the AuNps was estimated by using the Scherrer equation:

$$
B(2 \theta)=K \lambda / L \cos \theta
$$

where $B$-reflection full width at half maximum, $\lambda=1.54056 \AA$, $L$-size of crystallites. The value of the Scherrer constant $K$ has been set to 1 [40]. The same 
procedure of the instrumental profile and the background subtraction were applied to three analysed samples.

\section{Fourier Transform Infrared Spectroscopy (FT-IR)}

The media containing AuNPs were separated from cyanobacterial cells after $24 \mathrm{~h}$ of incubation and then centrifuged at $13,000 \mathrm{rpm}$ for $10 \mathrm{~min}$ in order to isolate the gold nanoparticles from the free proteins and other compounds present in the supernatant. The pellets of gold nanoparticles obtained after centrifugation were redispersed in deionized water and centrifuged again at 13,000 rpm for $10 \mathrm{~min}$ to isolate the gold nanoparticles. Thus, the obtained AuNPs were lyophilized, then incorporated in $\mathrm{KBr}$ pellets and subjected to FT-IR measurements, which were carried out on a Nicolet Nexus (Thermo Scientific, Warszawa) spectrophotometer in the diffuse reflectance mode operating at a resolution of $4 \mathrm{~cm}^{-1}$.

\section{Transmission Electron Microscopy (TEM)}

Media rich in gold nanoparticles (after $24 \mathrm{~h}$ of incubation) were analysed by transmission electron microscopy (TEM). For this purpose, a drop of the supernatant was placed on a carbon-coated copper grid and allowed to dry. TEM micrographs were taken using an FEI Tecnai G2 20 X-TWIN instrument (University of Wroclaw, Faculty of Chemistry) at an accelerating voltage of $200 \mathrm{kV}$ using ES Vision analysis software.

\section{Scanning Electron Microscopy (SEM)}

After 14 days of cultivation, the control and cultures of A. laxa brought into contact with gold ions were centrifuged at $5000 \mathrm{rpm}$ for $1 \mathrm{~min}$. Then, the cells were separated from the post-culture media and washed three times with sterile doubledistilled water. The pellet was suspended in a $3 \%$ solution of glutaraldehyde in $0.2 \mathrm{M}$ phosphate buffer ( $\mathrm{pH}$ 6.8-7.4) and placed at $4{ }^{\circ} \mathrm{C}$ overnight. Next, the cells were washed three times with $0.1 \mathrm{M}$ phosphate buffer $(\mathrm{pH}=7.2)$, suspended in a $1 \%$ solution of osmium tetroxide in $0.1 \mathrm{M}$ phosphate buffer and left for $2 \mathrm{~h}$ in the dark. After this time, the cells were washed three times with $0.1 \mathrm{M}$ phosphate buffer and their sequential dehydration with 50,60 and 70\% ethanol was carried out. After this step, the samples were lyophilized, placed on carbon tape and covered by carbon. SEM and EDS analysis were performed using a scanning electron microscope (Hitachi TM 3000, Warszawa, Poland) at voltage beam of $5.15 \mathrm{keV}$, resolution $\sim 30 \mathrm{~nm}$, magnification up to 30,000, using Quantax 70 analysis software. 


\section{Results}

\section{Viability of A. laxa}

The growths of $A$. laxa after its exposure to $\mathrm{HAuCl}_{4}$ are shown in Fig. 1. The measurements of the chlorophyll content show that at all tested concentrations, the growth of A. laxa was inhibited. The cells were able to grow slowly only in the presence of $0.01 \mathrm{mM}$ of $\mathrm{Au}^{3+}$ ions. The next two concentrations 0.05 and $0.1 \mathrm{mM}$ cause a systematic decrease of chlorophyll content. The most rapid changes occurred when the two highest concentrations were used, and in those samples within $24 \mathrm{~h}$ of incubation, the A. laxa cells died.

\section{Production of AuNPs by A. laxa}

The colour of the media (BG11) containing living A. laxa and those supplemented with $\mathrm{HAuCl}_{4}$ up to the final concentrations of $0.1 ; 0.5$ and $1.0 \mathrm{mM}$ changed from colourless to intense blue, violet and brown-violet, respectively, within $24 \mathrm{~h}$ of exposure (Fig. 2a). However, upon cultivation for fourteen days, all the cultures turned purple independent of the concentration of tetrachloroaurate ions (Fig. 2b).

To verify the presence of AuNPs, the culture media were examined by UV-Vis after $24 \mathrm{~h}$ of incubation. The resulting spectra showed broad and intensive peaks in the range of 500-600 nm, with SPR maxima at approximately 545 and $560 \mathrm{~nm}$ for 0.5 and $1 \mathrm{mM}$ of $\mathrm{HAuCl}_{4}$, respectively, and broad peaks at $600-650 \mathrm{~nm}$ with an SPR maximum at $620 \mathrm{~nm}$ for the lowest concentration (Fig. 3a). The maxima of the recorded SPR were in accordance with the characteristic maxima of SPR recorded for gold nanoparticles of variable morphology [41]. After fourteen days of cultivation, the post-culture media were examined again. This time, only the spectra

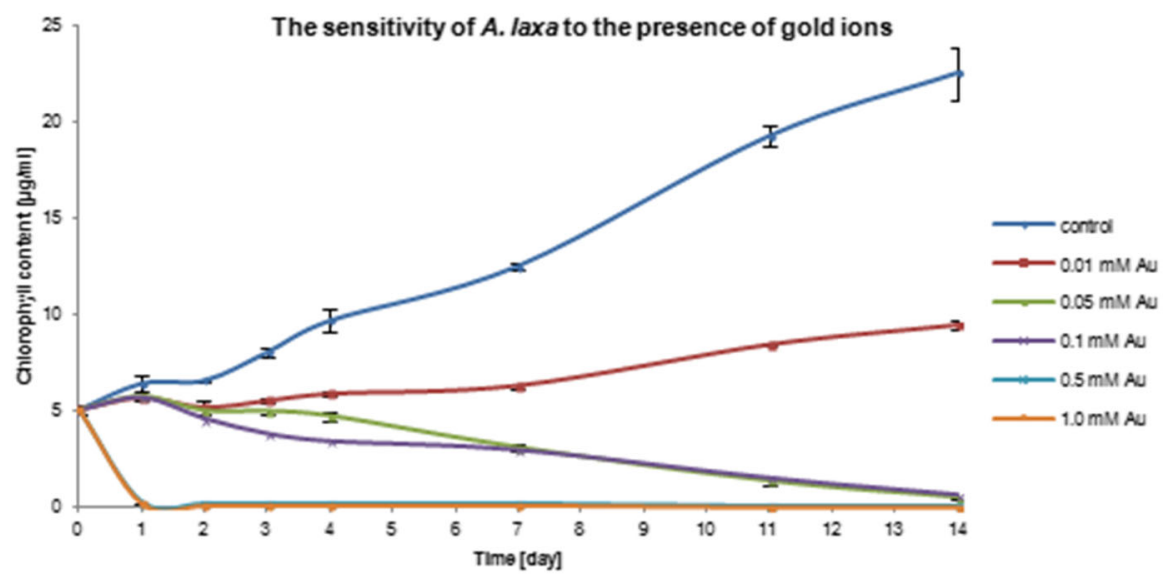

Fig. 1 Sensitivity of $A$. laxa to the presence of five concentrations of $\mathrm{HAuCl}_{4}$. The sensitivity is expressed as a function of chlorophyll content, which is one of the indicators of cyanobacterial metabolic activity 




Fig. 2 Biosynthesis of gold nanoparticles by A. laxa. The colour of the media containing $0.1,0.5$ and $1 \mathrm{mM}$ gold ions as the result of AuNP production. The picture in a presents the cultures with AuNPs obtained after $24 \mathrm{~h}$ of incubation, and $\mathbf{b}$ presents the cultures on the 14th day. The conversion of gold ions was obtained in all the cases
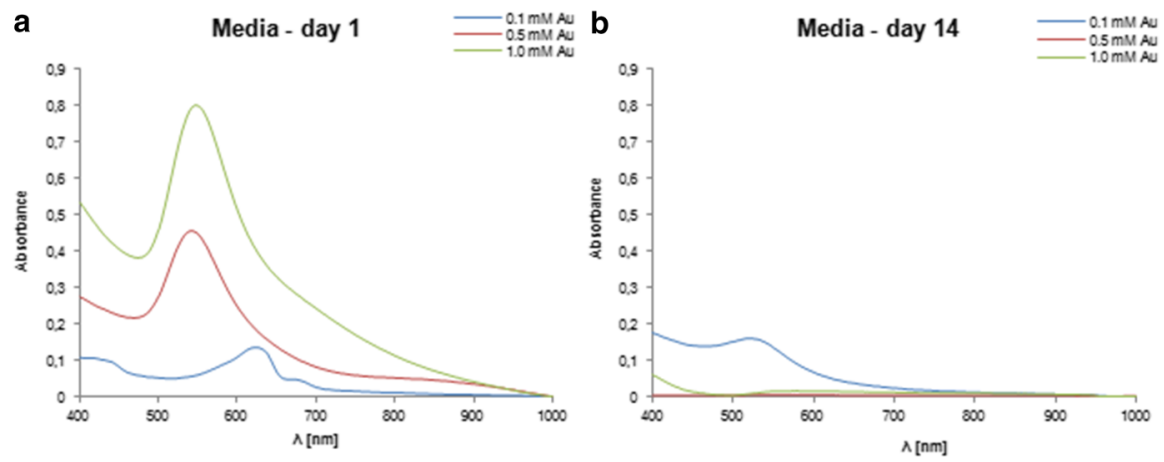

Fig. 3 UV-vis spectra of media recorded after $24 \mathrm{~h}$ (a) and on the 14th day (b) of the incubation of $A$. laxa with gold ions. The spectra show the presence of AuNPs in the media after a short time and their disappearance after the longer time of incubation. The latter was caused by the co-aggregation of nanoparticles within the cyanobacterial biomass

of the medium supplemented with the lowest concentration of gold salt showed one peak at $520 \mathrm{~nm}$ (Fig. 3b).

The XRD pattern of AuNPs, formed by A. laxa cells, showed reflections characteristic for the crystalline gold structure in all three tested samples (Fig. 4). The angular positions of the Bragg's reflections at $38.2^{\circ}, 44.3^{\circ}$ and $64.6^{\circ} 2 \theta$ angles corresponding to (111), (200) and (220) Miller indices, respectively, indicate the face-centred cubic (FCC) structure (Joint Committee on Power Diffraction Standard (JCPDS), file No. 04-0784) of the obtained gold nanoparticles. The remaining reflections are due to other crystalline phases present after the lyophilization process. On the basis of the Scherrer equation the approximate size of the particles in all three samples differentiated by the initial concentration of gold ions was estimated. The well-separated (220) reflection was chosen for the analysis in order to reasonably calculate the reflections' full width at half maximum. The approximate AuNPs size increases from 14.4 to 19.8 and $23.4 \mathrm{~nm}$ alongside with the increase of the $\mathrm{Au}^{3+}$ ions concentration in the initial samples from 0.1 through 0.5 to $1.0 \mathrm{mM}$, respectively.

\section{Morphology of AuNPs by Transmission Electron Microscopy (TEM)}

The result obtained from the TEM analysis proved the presence of gold nanoparticles of variable morphology, which were produced during $24 \mathrm{~h}$ of incubation of A. laxa with hydrogen tetrachloroaurate. The morphology of these 


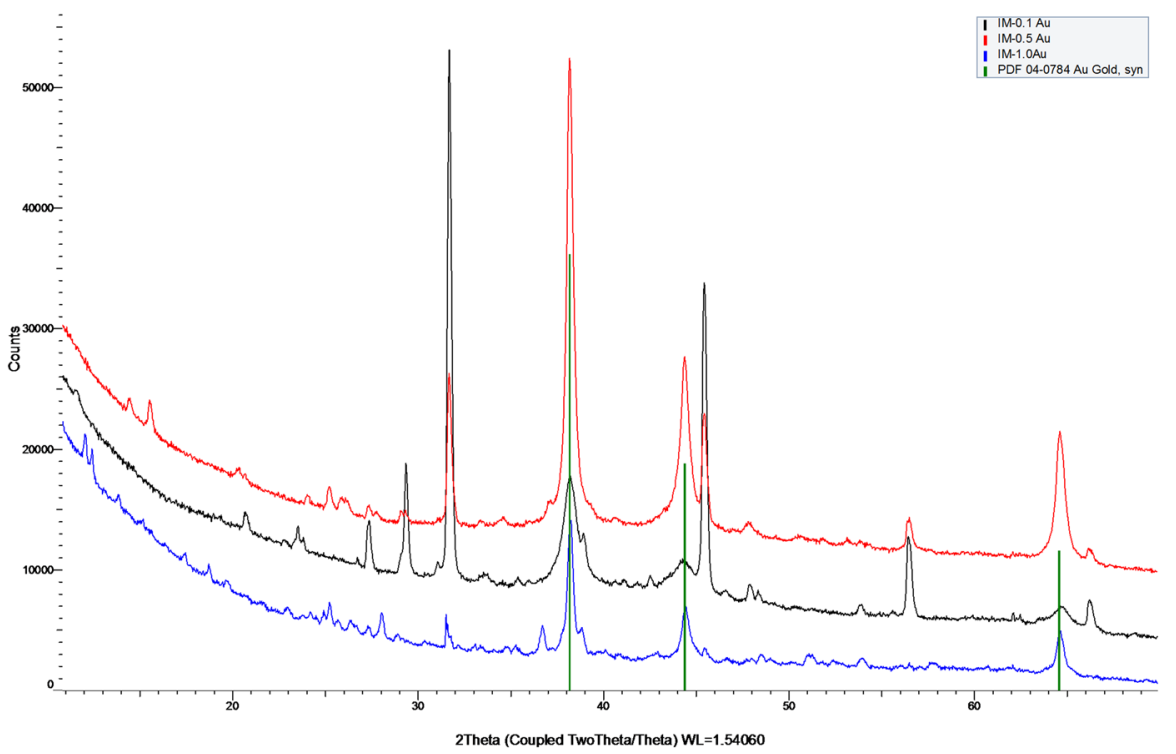

Fig. 4 XRD patterns of biosynthesized AuNPs using A. laxa cells

results is strongly dependent on the starting concentration of gold ions in media. Appropriate colouring of their solutions also indicates their formation. The medium characterized by blue colours (initial concentration of metal ions of $0.1 \mathrm{mM}$ ) contained small and spherical gold nanoparticles approximately $3-5 \mathrm{~nm}$ in diameter (Fig. 5a-c). The morphology of the nanoparticles formed at the two higher concentrations, 0.5 and $1.0 \mathrm{mM}$ (brown-violet), was more diverse. Generally, NPs appearing at $0.5 \mathrm{mM}$ (intense purple colour) were spherical (Fig. $5 \mathrm{~d}-\mathrm{f}$ ), but nevertheless other shapes were also present, e.g., triangular (Fig. 5e, f), hexagonal (Fig. 5e) and irregular. The sizes of these nanoparticles mostly ranged from 0 to $30 \mathrm{~nm}$, however the larger NPs with sizes from 30 to $100 \mathrm{~nm}$ were present. At the highest concentration of gold salt $(1.0 \mathrm{mM})$, the solution reached a brown-purple colour, and the presence of triangular (Fig. $5 \mathrm{~g}$, i), hexagonal (Fig. $5 \mathrm{~g}$, i) and irregular (Fig. 5h) forms of nanoparticles, most of them ranging from 20 to $50 \mathrm{~nm}$ and more than $100 \mathrm{~nm}$ in size, were recorded. Because of the various shape of nanoparticles obtain in two higher concentrations of gold ions in the given size range only the longest dimension was included. Additionally, the presence of single nanoparticles approximately $300 \mathrm{~nm}$ in size was noticed in this medium.

\section{FT-IR Studies}

FT-IR measurements were carried out in order to identify the capping agents responsible for the stability of the biogenic nanoparticles. The spectra of AuNPs obtained after $24 \mathrm{~h}$ of cultivation for the two tested concentrations $(0.1$ and $1 \mathrm{mM}$ of $\mathrm{Au}^{3+}$ ) show a complex pattern of bands from 3450 to $830 \mathrm{~cm}^{-1}$ (Fig. 6). The peak at approximately $3400-3448 \mathrm{~cm}^{-1}$ was assigned to the $\mathrm{O}-\mathrm{H}$ stretching frequency. 

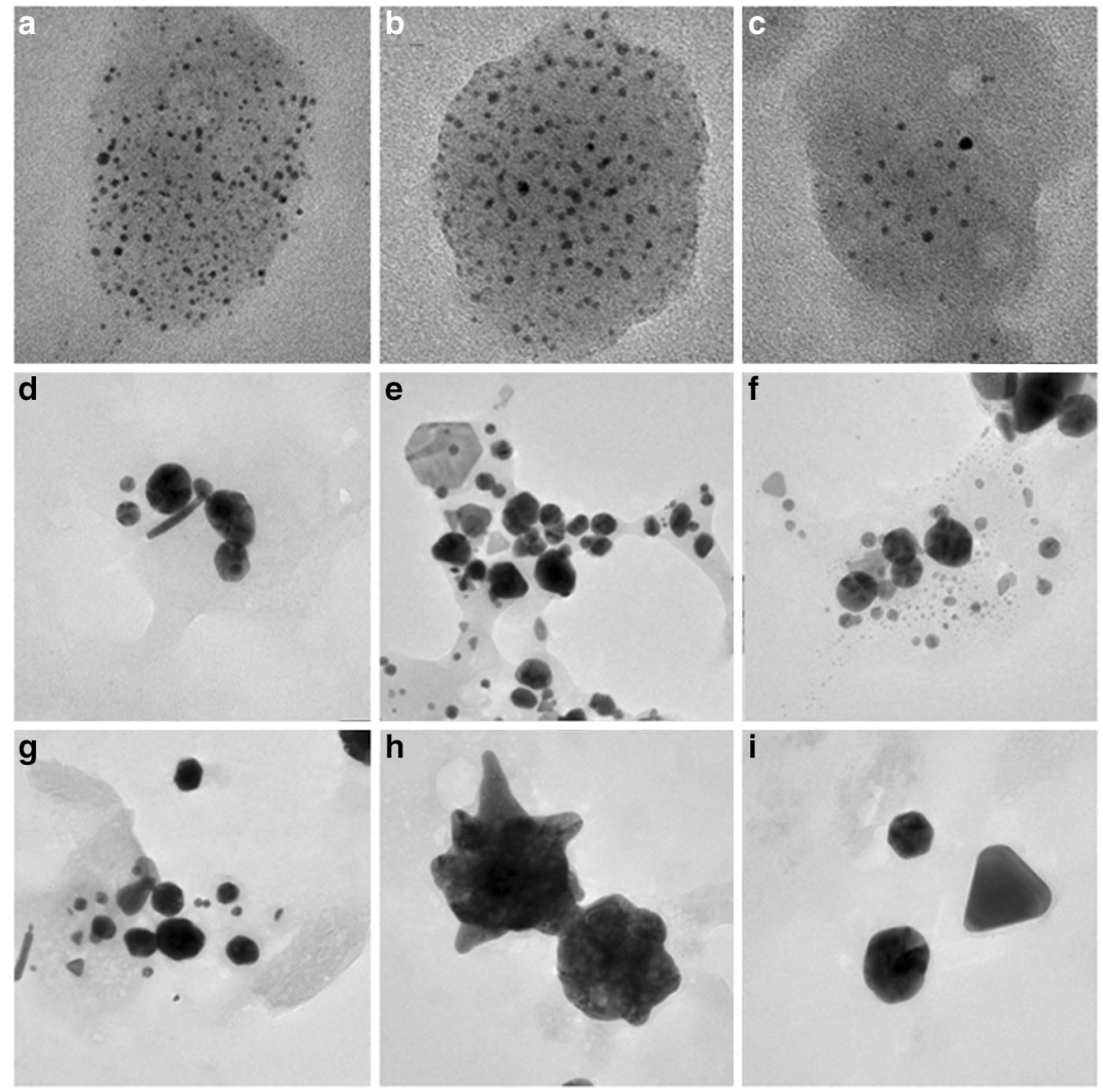

Fig. 5 TEM micrographs of gold nanoparticles found in cyanobacterial cultures after $24 \mathrm{~h}$ of incubation of $A$. laxa cells with $\mathrm{HAuCl}_{4}$. The images a-c present the nanoparticles obtained in media containing the lowest concentration of gold ions $(0.1 \mathrm{mM})$; the images $\mathbf{d}-\mathbf{f}$ present nanoparticles in experiments with $0.5 \mathrm{mM}$ of $\mathrm{Au}^{3+}$; and images $\mathbf{g}-\mathbf{i}$ show the nanoparticles obtained in experiments using $1.0 \mathrm{mM}$ of $\mathrm{Au}^{3+}$. Scale bars a-c $10 \mathrm{~nm}, \mathbf{d}-\mathbf{f} 50 \mathrm{~nm}, \mathbf{g} 100 \mathrm{~nm}, \mathbf{h}, \mathbf{i} 50 \mathrm{~nm}$

The weak absorptions at 2924 and $2854 \mathrm{~cm}^{-1}$ correspond to the asymmetrical and symmetrical $\mathrm{C}-\mathrm{H}$ stretching vibrations of aliphatic $\mathrm{CH}_{2}$. They suggest the organic nature of the AuNP capping layer. This conclusion seemed to be confirmed by the presence of the peak at approximately $1400-1380 \mathrm{~cm}^{-1}$ that corresponds to the C$\mathrm{H}$ bending of aliphatic $\mathrm{CH}_{2}$, medium-broad $\mathrm{C}-\mathrm{O}$ stretching and $\mathrm{C}-\mathrm{H}$ deformation, which are observed at $1040-1074 \mathrm{~cm}^{-1}$, and the peak at $1636 \mathrm{~cm}^{-1}$, which relates to the stretching vibration of the carboxylic group. 


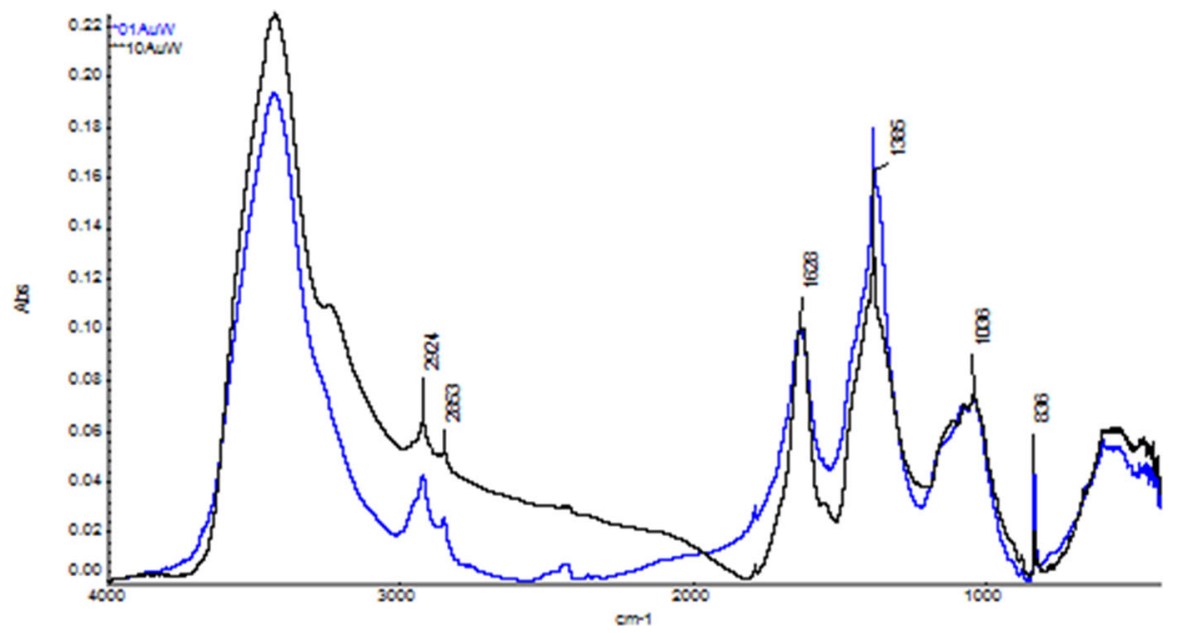

Fig. 6 The FT-IR spectra of biosynthesized AuNPs. The spectra were recorded for NPs obtained during $24 \mathrm{~h}$ of cultivation and separated from the media (blue line $-0.1 \mathrm{mM}$; black line $-1 \mathrm{mM}$ of $\mathrm{Au}^{3+}$ ). The presence of the bands confirmed the organic character of the capping agent

\section{Colloidal Stability in Case of Initial or Permanent Presence of Living Cells of A. laxa}

The formation of nanoparticles was examined in two systems: (1) in the cultures, where the cells were left during whole seven-day-long period of incubation (permanent mediation), and (2) in the cultures from which the cyanobacterial cells were removed after $24 \mathrm{~h}$ and the culture medium containing gold ions was left for the next several days (initial mediation). The UV-Vis spectra recorded for the media contained living cyanobacterial cells have shown that nanoparticles were formed during the first $24 \mathrm{~h}$ of the process and were found up to the fourth day of incubation. However, the intensity of the peaks recorded at approximately $550 \mathrm{~nm}$ for solutions of the concentrations of 0.5 and $1 \mathrm{mM}$ of gold cations decreased gradually. The intensity of the peaks reached their maximum at approximately $620 \mathrm{~nm}$, which reflects the amount of AuNPs formed in solutions at the concentration of $0.1 \mathrm{mM}$ gold cations and did not change significantly in that period of time. The measurements performed at the 7th day showed the shift of the maximum of the absorption from 620 to $520 \mathrm{~nm}$ in the case of $0.1 \mathrm{mM}$ of $\mathrm{Au}^{3+}$ and the disappearance of the peak characteristic for the presence of gold nanoparticles in cultures containing gold ions at concentration of $0.5 \mathrm{mM}$ (Fig. 7a, b). In experiments where the initial concentration of $\mathrm{Au}^{3+}$ was $1 \mathrm{mM}$, a small amount of AuNPs seemed to be still present (Fig. 7c). Surprisingly, the spectra of the system lacking in cyanobacterial cells showed different phenomenon. At the lowest concentration of gold ions, the maximum SPR peaks, at approximately $620 \mathrm{~nm}$, showed decreasing intensity in each subsequent day of the experiment. Interestingly, however, in this case the UV-Vis spectra recorded at the 7th day of incubation showed that the maximum of the absorption was shifted to a shorter 

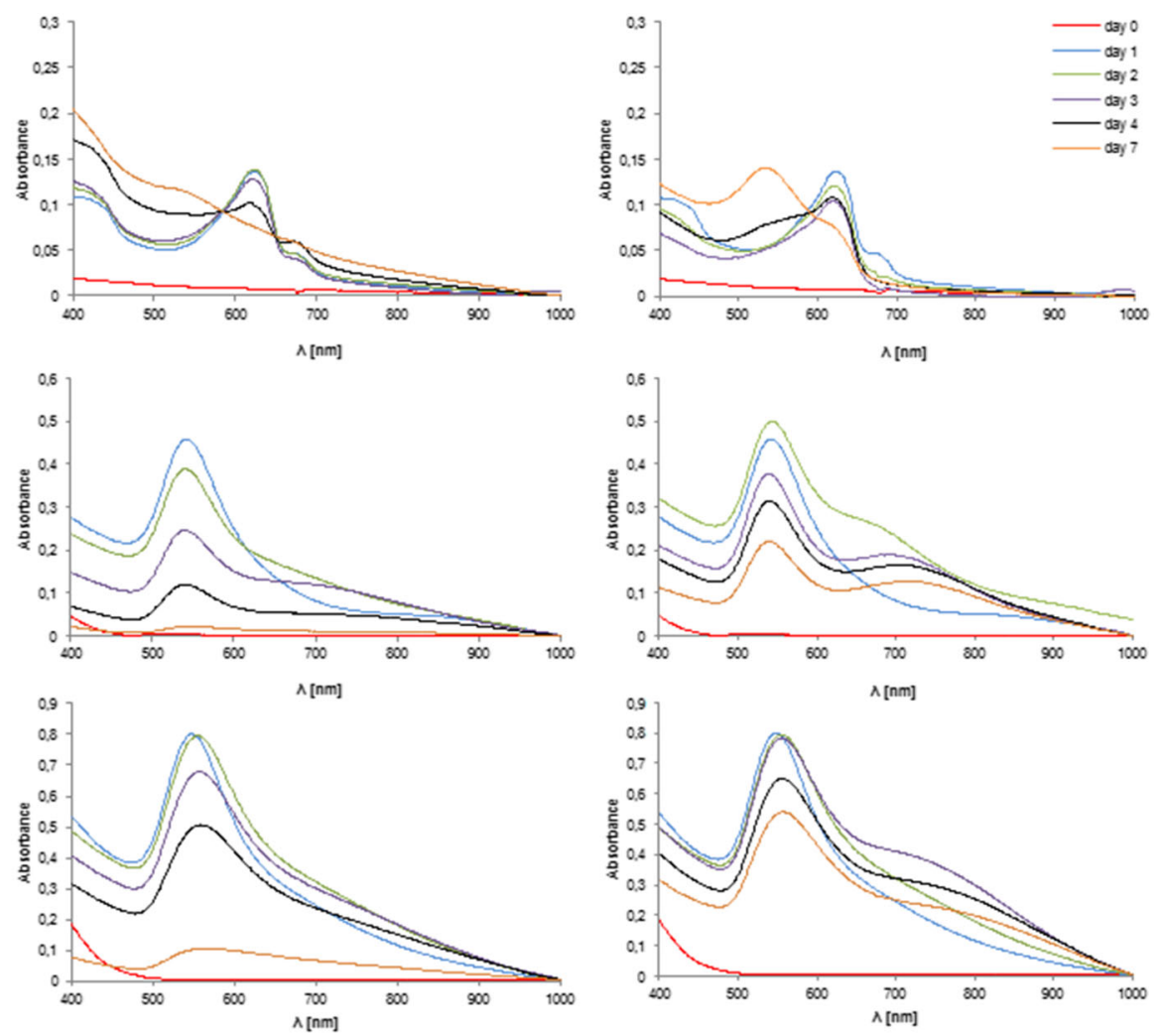

Fig. 7 The time course UV-Vis spectra of the media supplemented with $\mathrm{Au}^{3+}$ ions. Spectra were recorded for three concentrations, $0.1,0.5$ and $1 \mathrm{mM} \mathrm{HAuCl}_{4}$, when cultivating $A$. laxa permanently (a, $\mathbf{b}, \mathbf{c})$ and initially $(\mathbf{d}, \mathbf{e}, \mathbf{f})$. Spectra were recorded from the beginning of experiments (day 0) up to one week of incubation (up to day 7)

wavelength, approximately $530 \mathrm{~nm}$ (Fig. 7d). In the experiments carried out in the presence of 0.5 and $1 \mathrm{mM}$ of gold ions, the maxima of the absorption were recorded at approximately $550 \mathrm{~nm}$. They increased in intensity on the second day in the case of $0.5 \mathrm{mM}$ but did not change up to fourth day in the case of $1 \mathrm{mM}$ of gold ions. After that time, the intensities of the mentioned peaks were gradually decreased but to a significantly lesser extent than in the experiments with permanent mediation. Moreover, beginning from the third day of incubation, the appearance of broad peaks in the range of $650-820 \mathrm{~nm}$ was recorded in both experimental systems (Fig. 7e, f).

\section{Recovery of AuNPs from Cyanobacterial Biomass}

In addition to the cultures supplemented with the lowest tested concentration of $\mathrm{Au}^{3+}(0.1 \mathrm{mM})$, in which a light pink colour was observed, the media of all other cultures became almost colourless after the removal of the biomass. The UV-Vis spectra of the culture media recorded at the 14th day of incubation (Fig. 3b) showed 
that only in the media containing $0.1 \mathrm{mM}$ of gold ions were the AuNPs present at a measurable level. These results suggest that the AuNPs that formed in cultures containing higher concentrations of gold ions lost their colloidal stability. The question of the fate of the gold nanoparticles which were undoubtedly also formed in the cultures containing gold ions at concentrations of 0.5 and $1 \mathrm{mM}$ at the beginning of the incubation were answered when the cyanobacterial cells were observed under an optical microscope. Thus, at the 14th day of incubation, the cells became colourless; the mucilages composed mainly of exopolysaccharides (EPS), obtained a pink-violet colour characteristic for the nanogold (Fig. 8b).

Scanning electron microscopy (SEM) coupled with energy dispersive spectroscopy (EDS) indicated white dots/fields seen on microphotographs as created from gold nanoparticles or aggregates (Fig. 9e, f). In the microphotographs of the control cells and growing in the presence of gold ions at the lowest tested concentration (Fig. 9a, b), the AuNPs aggregates were not detected. Contrary to this result, the accumulation of gold nanoparticles around the cyanobacterial cells was observed in samples containing 0.5 and $1.0 \mathrm{mM}$ of gold ions (Fig. 9c, d). This finding confirmed the accumulation of AuNPs around the cells and consequently their limited dispersion in the medium.

To verify this finding, we extracted gold nanoparticles from the surfaces of the cells that had been separated from the media performed UV-Vis measurements on the extracts. Only the spectra of the extracts obtained from the cells cultured in the presence of $1 \mathrm{mM}$ of $\mathrm{Au}^{3+}$ ions, comprising the broad peak in the range from 500 to $600 \mathrm{~nm}$ with maximum of SPR approximately $550 \mathrm{~nm}$, are significant (Fig. 10). For the $0.5 \mathrm{mM}$ group, a similar local maximum of the spectrum was recorded, but in a much less evident manner. The lack of such a maximum was seen in the case of $0.1 \mathrm{mM}$ cultures. These results are in good accordance with the results of the UVVis analysis and confirm that the lack of colloidal stability of AuNPs in the cultures with higher initial concentration of gold cations is correlated with their presence in the EPS layer.

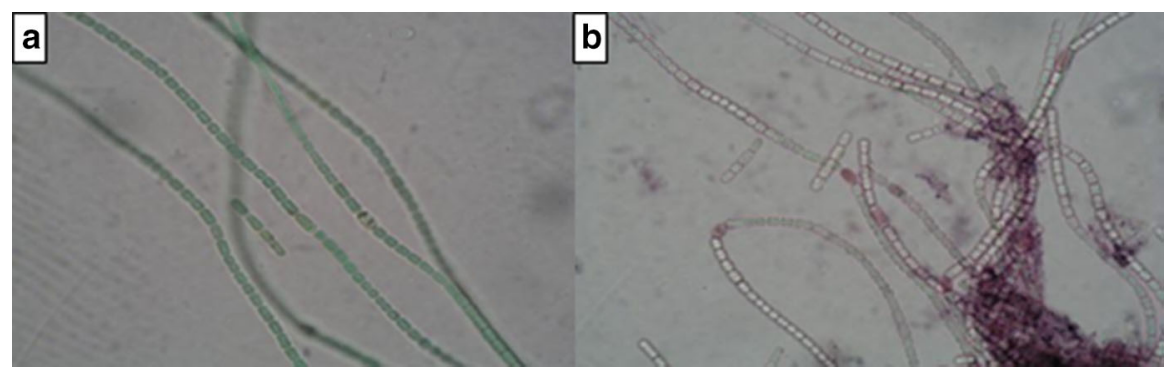

Fig. 8 Photographs from optic microscope (magnification $1000 \times$ ) of A. laxa: control (a) and cells surrounded by gold-treated EPS (b). The photographs were taken at 14th day of incubation; both the control and sample contained the highest tested $(1 \mathrm{mM})$ gold ion concentration 

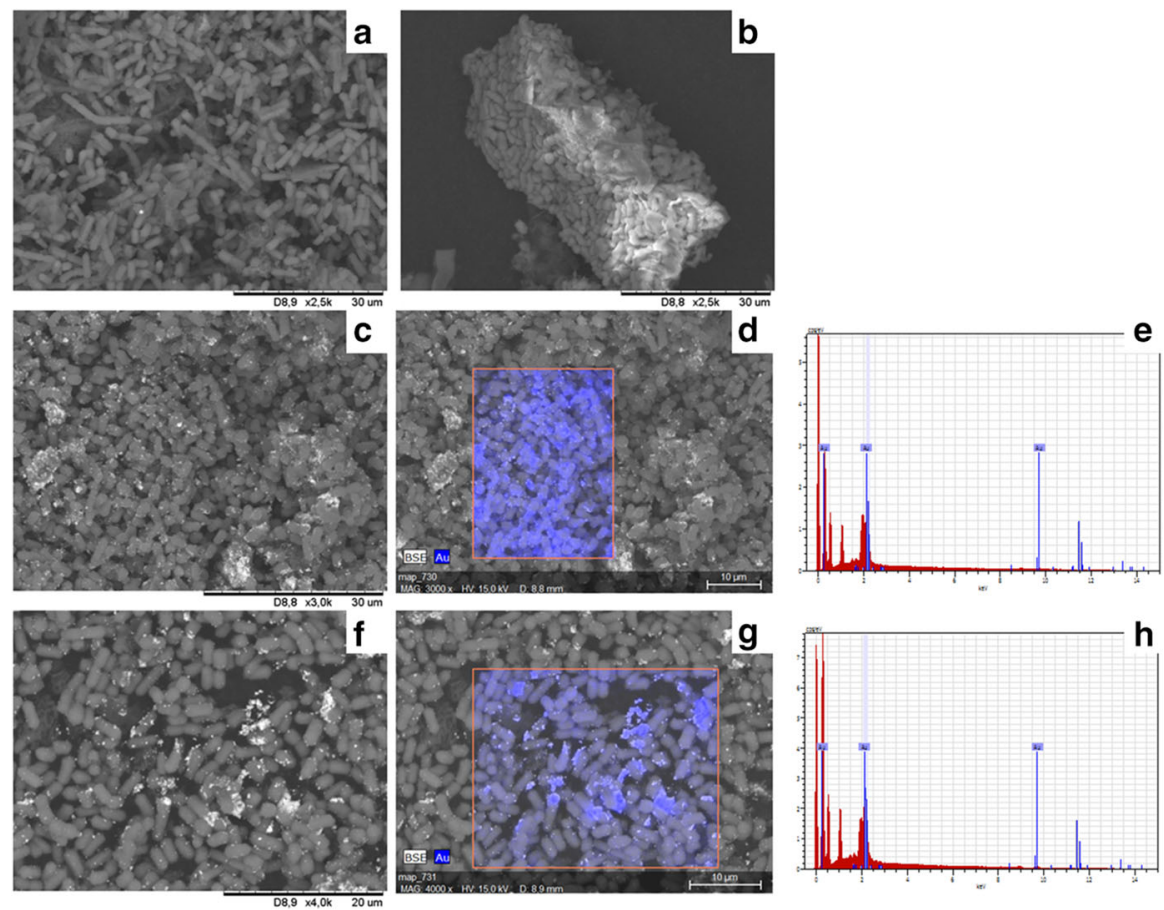

Fig. 9 The SEM microphotographs of the cells of A. laxa. The microphotographs were obtained from the control (a) and the cells grown in presence of $0.1(\mathbf{b}), 0.5$ (c) and $1 \mathrm{mM}$ of $\mathrm{Au}^{3+}$ (f). The presence of gold was indicated by mapping the surface for gold by EDS in the case of cells growing in the presence of 0.5 (d) and $1.0 \mathrm{mM}(\mathbf{g})$ of $\mathrm{Au}^{3+}$. The EDS spectra (e, $\mathbf{h}$ for 0.5 and $1.0 \mathrm{mM} \mathrm{Au}{ }^{3+}$ respectively) with elemental gold distribution along with the SEM results confirming the presence of AuNP. Scale bars $\mathbf{a}-$ $30 \mu \mathrm{m}, \mathbf{b}-30 \mu \mathrm{m}, \mathbf{c}-30 \mu \mathrm{m}, \mathbf{d}-10 \mu \mathrm{m}, \mathbf{f}-20 \mu \mathrm{m}$ and $\mathbf{g}-10 \mu \mathrm{m}$

\section{Synthesis of AuNPs by Deactivated Cells}

The $24 \mathrm{~h}$ of incubation of gold ions with metabolically inactive cells caused the changes in the colour of the supernatant independent of the method of deactivation of the cyanobacterial cells. The colours obtained after incubation of the cells inactivated by low temperature were characteristic for the presence of AuNPs: light purple in the $1.0 \mathrm{mM}$ and purple in the $0.5 \mathrm{mM}$ solutions. The media containing the lowest tested concentration of $\mathrm{Au}^{3+}(0.1 \mathrm{mM})$ were colourless. In the case of autoclaved cells, the colours of the appropriate supernatants were pink, intense purple and purple, respectively, for $\mathrm{Au}^{3+}$ at $1.0,0.5$ and $0.1 \mathrm{mM}$. The presence of gold nanoparticles was confirmed by UV-Vis measurements (Fig. 11). The spectra showed a broad peak at 500-600 nm for all three concentrations of AuNPs in the experiments with autoclaved cells and in two higher concentrations of gold ions in the media obtained when frozen cells were used. The SPR maxima were in accordance with those, which are characteristic for gold nanoparticles [41]; nevertheless, appropriate signals were of low intensity in comparison to the SPR peaks recorded for the AuNPs produced by living cyanobacterial cells. 


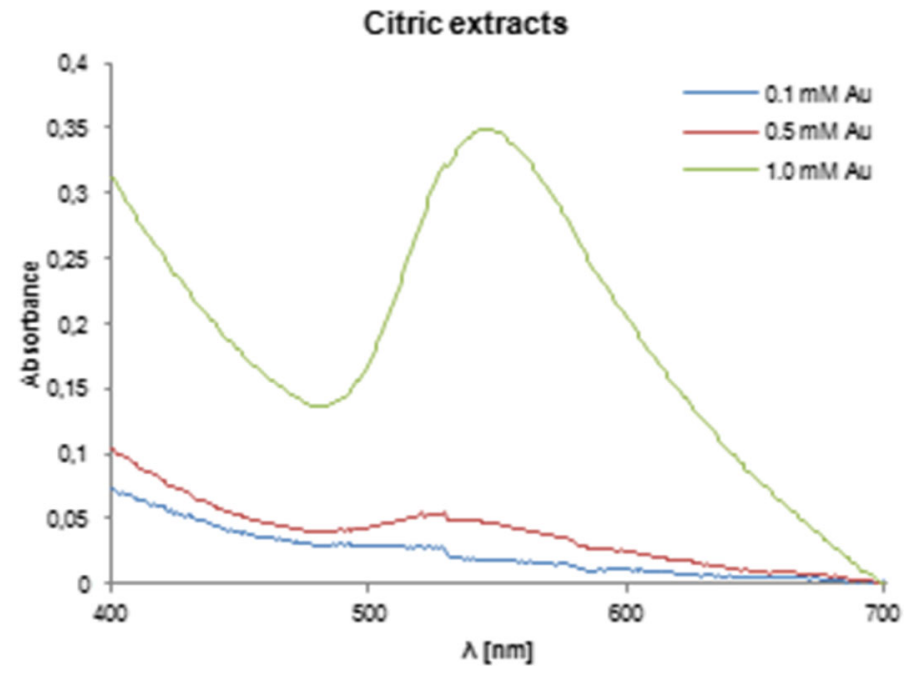

Fig. 10 The representative UV-vis spectra of the sodium citrate extracts. The extracts contain AuNPs separated from the cells from the fourteen days old cultures of A. laxa, incubated in three various concentrations of gold ions
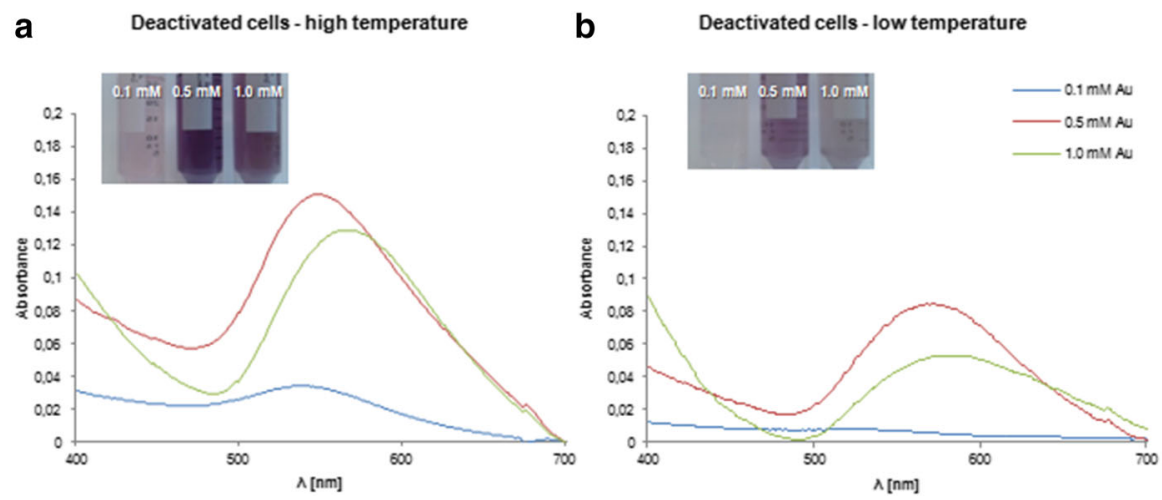

Fig. 11 UV-vis spectra of AuNPs produced by metabolically inactive A. laxa. Experimental samples obtained after $24 \mathrm{~h}$ of contact with $A$. laxa deactivated by autoclaving (a) and freezing (b) with $\mathrm{HAuCl}_{4}$

\section{Discussion}

The phenomenon of the formation of AuNPs by cyanobacteria that belong to the Anabaena genus was described only three time to date: by Dahoumane and coauthors in 2012 [29] regarding A. flos-aquae and by Rosken and co-authors in 2014 [28] and in 2016 [42] regarding Anabaena sp. and A. cylindrica respectively.

The viability of cyanobacterial cells in media containing $\mathrm{HAuCl}_{4}$ has shown that A. laxa is very sensitive towards gold ions. The culture can grow in its presence only at low concentrations ranging from 0.01 to $0.1 \mathrm{mM}$, whereas their higher concentrations are lethal. The results of experiments carried out by Dahoumane 
and co-authors proved that the sensitivity of photosynthesizing microorganisms towards gold ions was dependent on the tested species and on the $\mathrm{HAuCl}_{4}$ concentration [24, 29, 32]. Taking into account the present study, it may be stated that both A. laxa and A. flos-aquae are characterized by a similar sensitivity at $1.0 \mathrm{mM}$ of tetrachloroaurate, with A. laxa being more resistant to the action at $0.1 \mathrm{mM}$. Although the A. laxa was able to live at low concentrations of $\mathrm{HAuCl}_{4}$, colour changes were observed only at $0.1,0.5$ and $1.0 \mathrm{mM}$. Therefore, further experiments on the biosynthesis of gold nanoparticles were performed for these concentrations. The ability of biocatalytic gold nanoparticle formation by A. laxa was confirmed at first visually by the appearance of relevant colouring of growth media, the UV-Vis and XRD analysis.

In the case of A. flos-aquae grown in the presence of $\mathrm{HAuCl}_{4}$ at concentrations of 0.1 and $1 \mathrm{mM}$ [29], nanoparticles were present in media and inside the cells after 3 days of incubation. At the lower tested concentration of gold ions, the formation of spherical particles $8.1 \pm 2.1 \mathrm{~nm}$ in size was observed inside the cells, whereas those in the medium were $14.8 \pm 5.3 \mathrm{~nm}$ in size. At the $1 \mathrm{mM}$ concentration of gold ions, the observed particles possessed a spherical shape and size of $10.0 \pm 4.7 \mathrm{~nm}$ inside the cells. Additionally, triangular nanoparticles (size $7.9 \pm 1.5 \mathrm{~nm}$ ) were present on the surface of the cells, but no AuNPs were observed in the culture media [29]. Anabaena sp. was reported to produce mostly spherical nanoparticles with an average size of $9 \mathrm{~nm}$, even after $2 \mathrm{~h}$ of incubation with $0.8 \mathrm{mM}$ gold ions. These nanoparticles were formed mostly in the vegetative cells [28]. The results of this study have shown that $A$. laxa is able to produce gold nanoparticles within $24 \mathrm{~h}$ of incubation at all three tested concentrations. After this time, gold nanoparticles were mostly localized in the growth medium, which significantly facilitates their isolation. The yield of the as-produced AuNPs is dependent on the starting concentration of $\mathrm{Au}^{3+}$ in the culture, and the yield was two and three times higher in samples with concentrations of 0.5 and $1.0 \mathrm{mM}$, respectively, when compared to a medium of $0.1 \mathrm{mM}$ of $\mathrm{Au}^{3+}$. These results indicate that the yield of the biosynthesis carried out by A. laxa cells at the lowest gold concentration seemed to be higher than that obtained for A. flos-aquae. Regarding the kinetics of AuNP formation, it is seen that the rate of this process is highly independent of the starting concentration of gold ions, which was confirmed by the SPR maxima recoded after $24 \mathrm{~h}$ of incubation. These results differ from the kinetics obtained for A. flos-aquae, where the absorption intensity increased up to 13 days [29]. In addition, the bands recorded in the UV-Vis spectra after $24 \mathrm{~h}$ of maintenance $A$. laxa cultures at 0.5 and 1.0 concentrations of gold ions suggest that the obtained AuNPs possess various shapes instead of being spherical, as was observed for A. flos-aquae. For the lowest concentration of $\mathrm{Au}^{3+}$ after $24 \mathrm{~h}$ of incubation the colour of medium was blue and the maximum of SPR was recorded at $620 \mathrm{~nm}$. However after 7th day of incubation the maximum of SPR for the same sample was $520 \mathrm{~nm}$. This deviation may have two explanations. At first, the phycocyanobilin, the blue dye of cyanobacteria which the maximum of absorption is $620 \mathrm{~nm}$ [43]. During the reducing of gold ions this dye may be released to the medium as a result of disturbance of the integrity of cell walls and masks the presence of gold nanoparticles. Then after few days the phycocyanobilins started 
gradually decaying and the SPR at $520 \mathrm{~nm}$ was recorded. The second, the Suganya and co-authors indicate that excitation maximum at $620 \mathrm{~nm}$ may be due to HOMOLUMO intraband transitions of the nanoparticles [44]. At next days the size of nanoparticles probably was changed (they grew up) what caused the shift of SPF from $620 \mathrm{~nm}$ to $520 \mathrm{~nm}$.

The TEM analysis confirmed the formation of NPs of irregular shapes, which is the second major advantage of our study. Currently, the non-typical (non-spherical) shaped nanoparticles have attracted interest because their structural, optical, electronic, magnetic, and catalytic properties are different from spherical particles and allow wider applications [14]. Additionally, the smallest particles (size approximately $5 \mathrm{~nm}$ ), which were obtained in the cultures of A. laxa supplemented with the lowest tested concentration of gold ions $(0.1 \mathrm{mM})$, seemed to be a stable form of seed particles up to the fourth day after the reduction. These types of NPs are used in seed-growing synthesis [45, 46]. Based on TEM and XRD analysis the size of the particles increases with the increased concentration of gold ions in the initial solutions.

An interesting property of NPs biosynthesized by cyanobacteria is the organic capping that improves the stability of the obtained nanostructures. The TEM experiments, as well as FT-IR analysis, proved the existence of an organic layer that envelops the formed gold nanoparticles. Moreover, the FT-IR spectra of these nanoparticles are in good accordance with the spectra obtained by Parikh and Madamwar [47] for cyanobacterial exopolysaccharides (EPS). The high compatibility between the literature and our results strongly suggests the presence of cyanobacterial EPS as a cover of the surface of AuNPs. Therefore, the EPS can be considered capping agents, which supports the process of AuNPs biosynthesis and prevents them from aggregating. In addition, most EPS are water-soluble polymers [48], so their presence at the NP surface improves the stability of colloidal gold in aqueous solutions. Similar findings had been published by Dahoumane and coauthors, who indicated the important role of EPS produced by photosynthetic organisms in the stabilization of AuNPs [24, 29, 31]. Moreover, his recently published results show that besides EPS, the presence of lactate molecules in the medium may improve the stability of the as-produced AuNPs by algae [32].

The stabilities of the obtained forms of nanoparticles and the termination of the process of their formation were also studied. Therefore, the role of the removal of the biocatalyst from the medium was studied in the context of the stability of the obtained NPs in the presence or absence of cyanobacterial cells. As a result, we observed that the removal of $A$. laxa cells from media after $24 \mathrm{~h}$ of incubation did not stop the growth and development of the nanoparticles in the following days of the experiment. The appearance of additional bands between 700-800 nm (Fig. 7e, f) in the UV-Vis spectra related to growth or aggregation of the AuNPs confirmed such a change. This phenomenon was observed independently of the gold concentration, but the most significant modification was noticed at $0.1 \mathrm{mM}$ of $\mathrm{Au}^{3+}$. However, nanoparticles formed in media from which cyanobacterial cells were not removed did not grow in the case of the two higher concentrations. Over time, these nanostructures exhibited the tendency to accumulate in the proximity of the cell walls, mainly in the EPS layer. This phenomenon resulted in the lack of NP 
colloidal stability in the cultures containing 0.5 or $1.0 \mathrm{mM}$ and was the reason for the slow disappearance of the characteristic UV-Vis bands recorded for the culture media (Fig. 7a, b, c). Consequently, the trapping of NPs in the EPS layer caused the need for their recovery from the biomass. However, according to our results, the extraction of nanoparticles using the solution with sodium citrate (the standard method) was efficient only for the highest tested concentration $(1.0 \mathrm{mM})$ of gold ions.

The results of our experiments have shown that the modification of cyanobacterial media with three different concentrations of gold ions led to obtaining gold nanoparticles of diverse morphology and size. A similar effect was observed for $A$. flos-aquae, where two concentrations also resulted in distinct morphologies of AuNPs. Although both species, A. laxa and A. flos-aquae, belong to the same genus, to date there is no clear evidence if the species of cyanobacteria used as biocatalysts play an important role with respect to the shape of the formed NPs. Our results indicate that the conditions of the biosynthesis were a more significant factor influencing the final morphology and size of the obtained AuNPs. Similar conclusions were derived concerning A. flos-aquae [29] and Euglena gracilis [32].

In the case of $A$. flos-aquae, the authors provided the information that gold colloids formed even when the cells were damaged. They assumed that nanoparticles could be formed faster and easier due to loss of membrane integrity by the cells [29]. Thus, the deactivated cells should be deprived of the ability to form gold nanoparticles. The results of the experiment with deactivated cells showed the changes in the colours of the culture media in both systems, living and dead cyanobacterial cells, which confirmed the formation of the AuNPs independent of the cell status. However, the comparison of the intensities of the maxima of SPR bands in these two cases confirmed that the use of dead cells caused a significant decrease in the yield of AuNP formation.

\section{Conclusions}

The cyanobacterium A. laxa incubated with hydrogen tetrachloroaurate for $24 \mathrm{~h}$ is a good biocatalyst for the formation of gold nanoparticles of variable size and shape. The kinetics of this process is fast, and the AuNPs are formed with satisfactory yield. The increase in initial concentration of gold ions raises the efficiency of this process. The size and morphology of the nanostructures formed by A. laxa depend on the initial concentration of gold ions, which creates the opportunity to control this process. After $24 \mathrm{~h}$ of cultivation, nanostructures are localized mostly outside the cells, which is an advantage considering the subsequent separation of AuNPs from the biomass. The elongation of cultivation is accompanied with a decrease in the colloidal stability of the nanoparticles and their further trapping in the exopolysaccharide layer of the cyanobacterial cells. Bearing in mind all relevant results, we conclude that cyanobacteria play an important role in biocatalytic systems for the formation of variously shaped gold nanoparticles. 
Acknowledgements The authors acknowledge Prof. Paweł Kafarski for his inspiring mentoring and continuous willingness to help and discuss all doubtful issues. Presented research were partially supported in the frame of the Project PBS3/B8/25/2015, Granted by The National Centre for Research and Development in Poland.

\section{Compliance with Ethical Standards}

Conflict of interest The authors declare that they have no conflict of interest.

Open Access This article is distributed under the terms of the Creative Commons Attribution 4.0 International License (http://creativecommons.org/licenses/by/4.0/), which permits unrestricted use, distribution, and reproduction in any medium, provided you give appropriate credit to the original author(s) and the source, provide a link to the Creative Commons license, and indicate if changes were made.

\section{References}

1. M. C. Daniel and D. Astruc (2004). Chem. Rev. 104, 293-346.

2. A. Olenin and G. V. Lisichkin (2011). Russ. Chem. Rev. 80, 605-630.

3. C. J. Murphy, A. M. Gole, S. E. Hunyadi, and C. J. Orendorff (2006). Inorg. Chem. 45, 7544-7554.

4. Y. Sun and Y. Xia (2002). Science 298, 2176-2179.

5. S. Shankar, S. Bhargava, and M. Sastry (2005). J. Nanosci. Nanotech. 5, 1721-1727.

6. E. Hao, R. C. Bailey, G. C. Schatz, J. T. Hupp, and S. Li (2004). Nano Lett. 4, 327-330.

7. M. Treguer-Delapierre, J. Majimel, S. Mornet, E. Duguet, and S. Ravaine (2008). Gold Bull. 41, 195-207.

8. C. J. Murphy, A. M. Gole, S. E. Hunyadi, J. W. Stone, P. N. Sisco, A. Alkilany, B. E. Kinard, and P. Hankins (2008). Chem. Commun. 7, 544-557.

9. R. Narayanan and M. A. El-Sayed (2005). J. Phys. Chem. B. 109, 12663-12676.

10. N. Bi, Y. Chen, H. Qi, X. Zheng, and Y. Chen (2012). Sens. Actuators B. 166-167, 766-771.

11. M. J. Kwon, J. Lee, A. W. Wark, and H. J. Lee (2012). Anal. Chem. 84, 1702-1707.

12. Y. Zhang, G. Chang, S. Liu, W. Lu, and X. Sun (2011). Biosens. Bioelectron. 28, 344-348.

13. Y. B. Mollamahalle, M. Ghorbani, and A. Dolati (2012). Electrochim. Acta. 75, 157-163.

14. N. Li, P. Zhao, and D. Astruc (2014). Angew. Chem. Int. Ed. 53, 1756-1789.

15. M. F. Lengke, C. Sanpawanitchakit, and G. Southam in M. Rai and N. Duran (eds.), Metal nanoparticles in microbiology (Springer, New York, 2011), p. 37.

16. X. Li, H. Xu, Z. S. Chen, and G. Chen (2011). J. Nanomater. 2011, 1-16.

17. E. C. Dreaden, A. M. Alkilany, X. Huang, C. J. Murphy, and M. A. El-Sayed (2012). Chem. Soc. Rev. 41, 2740-2779.

18. J. You, R. Zhang, G. Zhang, M. Zhong, Y. Liu, C. S. Van Pelt, D. Liang, W. Wei, A. K. Sood, and C. Li (2012). J. Control Release. 158, 319-328.

19. R. Bardhan, W. Chen, C. Perez-Torres, M. Bartels, R. M. Huschka, L. L. Zhao, E. Morosan, R. G. Pautler, A. Joshi, and N. J. Halas (2009). Adv. Funct. Mater. 19, 3901-3909.

20. L. Dykman and N. Khlebtsov (2012). Chem. Soc. Rev. 41, 2256-2282.

21. B. K. Salunke, S. S. Sawant, S. Lee, and B. S. Kim (2016). World J. Microbiol. Biotechnol. 32, 1-16.

22. S. A. Dahoumane, E. K. Wujcik, and C. Jeffryes (2016). Enz. Microb. Tech. 95, 13-27.

23. A. Sharma, S. Sharma, K. Sharma, S. P. K. Chetri, A. Vashishtha, P. Singh, R. Kumar, B. Rathi, and V. Agrawal (2016). J. App. Phycol. 28, 1759-1774.

24. S. A. Dahoumane, C. Yepremian, C. Djediat, A. Coute, F. Fievet, T. Coradin, and R. Brayner (2014). J. Nanop. Res. 16, 1-12.

25. P. Kuppusamy, M. M. Yusoff, G. P. Maniam, and N. Govindan (2016). Saudi Pharm. J. 24, 473-484.

26. P. Mohanpuria, N. K. Rana, and S. K. Yadav (2008). J. Nanopart. Res. 10, 507-517.

27. K. B. Narayanan and N. Sakthivel (2010). Adv. Colloid Interface Sci. 156, 1-13.

28. L. M. Rosken, S. Korsten, C. B. Fischer, A. Schonleber, S. Smaalen, S. Geimer, C. Beresko, G. Ankerhold, and S. Wehner (2014). J. Nanopart. Res. 16, 1-14.

29. S. A. Dahoumane, C. Djediat, C. Yepremian, A. Coute, F. Fievet, T. Coradin, and R. Brayner (2012). J. Nanopart. Res. 14, 1-17. 
30. R. Brayner, H. Barberousse, M. Hernadi, C. Djedjat, C. Yepremian, T. Coradin, J. Livage, F. Fiévet, and A. Couté (2007). J. Nanosci. Nanotechnol. 7, 2696-2708.

31. S. A. Dahoumane, K. Wijesekera, C. D. M. Filipe, and J. D. Brennan (2014). J. Colloid Interface Sci. 414, 67-72.

32. S. A. Dahoumane, C. Yepremian, C. Djediat, A. Coute, and F. Fievet (2016). J. Nanop. Res. 18, 1-12.

33. T. Kalabegishvili, I. Murusidze, E. Kirkesali, A. Rcheulishvili, E. Ginturi, N. Kuchava, N. Bagdavadze, E. Gelagutashvili, M. V. Frontasyeva, I. Zinicovscaia, S. S. Pavlov, and A. Y. Dmitriev (2013). Ecol. Chem. Eng. S. 20, 621-631.

34. U. K. S. Suganya, K. Govindaraju, V. Ganesh Kumar, T. Stalin Dhas, V. Karthick, G. Singaravelu, and E. Manickan (2015). Mater. Sci. Eng. C 47, 351-356.

35. D. Parial, H. K. Patra, P. Roychoudhury, A. K. Dasgupta, and R. Pal (2012). J. Appl. Phycol. 24, 55-60.

36. D. Parial, H. K. Patra, A. K. Dasgupta, and R. Pal (2012). Eur. J. Phycol. 47, 22-29.

37. G. Forlani, V. Prearo, D. Wieczorek, P. Kafarski, and J. Lipok (2011). Enz. Microb. Tech. 48, 299-305.

38. H. K. Lichtenthaler (1987). Methods Enzymol. 148, 350-382.

39. D. Parial and R. Pal (2014). Indian J. Appl. Res. 4, 69-72.

40. J. I. Langford and A. J. C. Wilson (1978). J. Appl. Cryst. 11, 102-113.

41. P. Strobbia, E. Languirand, and B. M. Cullum (2015). Opt. Eng. 54, 1-22.

42. L. M. Rosken, F. Cappel, S. Korsten, C. B. Fischer, A. Schonleber, S. van Smaalen, S. Geimer, C. Beresko, G. Ankerhold, and S. Wehner (2016). Beilstein J. Nanotechnol. 7, 312-327.

43. M. Sobiechowska-Sasin, J. Stoń-Egiert, and A. Kosakowska (2014). J. Appl. Phycol. 26, 2065-2074.

44. U. K. S. Suganya, K. Govindaraju, V. Ganesh Kumar, T. Stalin Dhas, V. Karthick, G. Singaravelu, and M. Elanchezhiyan (2015). Mater. Sci. Eng. C. 47, 351-356.

45. C. Ziegler and A. Eychmuller (2011). J. Phys. Chem. C 115, 4502-4506.

46. A. Henkel, O. Schubert, A. Plech, and C. Sonnichsen (2009). J. Phys. Chem. C 113, 10390-10394.

47. A. Parikh and D. Madamwar (2006). Bioresource Technol. 97, 1822-1827.

48. R. De Philippis, C. Sili, R. Paperi, and M. Vincenzini (2001). J. Appl. Phycol. 13, 293-299. 